\title{
Intracranial Suppuration at the Brazzaville Academic Hospital
}

\author{
L. Boukassa*, H. B. Ekouele-Mbaki, O. B. Ngackosso, S. B. Kinata Bambino \\ Department of Surgery, Division of Neurosurgery, Brazzaville Academic Hospital, Brazzaville, Republic of Congo \\ Email: *lboukassalouf@gmail.com
}

How to cite this paper: Boukassa, L., Ekouele-Mbaki, H.B., Ngackosso, O.B. and Kinata Bambino, S.B. (2020) Intracranial Suppuration at the Brazzaville Academic Hospital. Neuroscience \& Medicine, 11, 36-44.

https://doi.org/10.4236/nm.2020.111005

Received: October 19, 2019

Accepted: March 27, 2020

Published: March 30, 2020

Copyright (c) 2020 by author(s) and Scientific Research Publishing Inc. This work is licensed under the Creative Commons Attribution International License (CC BY 4.0).

http://creativecommons.org/licenses/by/4.0/

\begin{abstract}
Background: Intracranial suppurations (ICS) due to banal germs are medical-surgical emergencies, despite their little removed frequency. Represented by abscesses and empyemas, their management has been improved by the combined contributions of new diagnostic and therapeutic methods. Objective: Appreciate the management of intracranial suppurations banal germ in our service. Material and methods: A retrospective study of 41 cases of intra-cranial suppurations was conducted at Brazzaville University Hospital, from January 2007 to June 2019. Diagnostic, therapeutic and evolution aspects have been studied. Results: They are divided into 24 empyemas, 8 abscesses and 9 associations abscess-empyema. The average age was 20.2 years old in general. The male predominance is noted in all groups. The sex ratio is 3.1 for all of these intracranial suppurations (ICS). They frequently complicated Oto-Rhino-Laryngology (ORL) infections (41.4\%). The clinic was mostly represented by the Bergman's triad $51.2 \%$, followed by headache $14.6 \%$ and seizures $12.2 \%$. The lesions were predominant in supratentorial $97.5 \%$. Frontal location was found in $67.4 \%$. Germs were isolated in $29.4 \%$ of samples. There were 5 Streptococci, 3 Staphylococci and 2 Gram-negative Bacilli. The medico-surgical treatment indicated in $80.5 \%$ combined often probabilistic tri-antibiotherapy with the evacuation of the pus by the trepano-puncture. Evolution under this treatment was marked by healing in $90.2 \%$. The lethality was 9.7\%. Conclusion: The pursuit of the improvement of these infections requires the adequate treatment of their gateways, most of them loco-regional.
\end{abstract}

\section{Keywords}

Intracranial Suppuration, Abscess, Empyema

\section{Introduction}

Intracranial suppurations (ICS), represented by abscesses and empyemas, are se- 
rious affections [1] [2]. Those due to banal germs are medico-surgical emergencies that have seen their prognosis improved by the combined contributions of new antibiotic molecules and new medical imaging techniques, namely Computed Tomography (CT) and Magnetic Resonance Imaging (MRI) [1] [2]. The latter made it possible to make early diagnosis of lesion and topography; to see their evolutionary stage, but also because of their safety, to improve their surveillance. These have made it possible to make an early diagnosis of lesions, to specify their topographies and their evolutionary stage, but also to improve their surveillance.

In Africa in general and south of the Sahara in particular [3] [4] [5], several publications have been made on this subject. The results include: young age of patients, frequency of the ORL origin front door, delayed diagnosis, low percentage of isolated germs, and trepano-puncture as the most common surgical treatment.

Through this study, we hope to contribute to a better knowledge of these affections, by relating their particularities in our environmental and professional context, as several African teams had done before us.

\section{Material and Method}

This is a retrospective study, going from June 2007 to June 2019 (12 years). During this period, 2053 patients had been hospitalized in the Neurosurgery Department of the University Hospital of Brazzaville in Congo. Of the 50 patients hospitalized for intracranial suppurations, 9 were parasitic in HIV patients and 41 were for banal germs.

In terms of lesions found in medical imaging, these patients were classified into three groups: that of abscesses, empyemas and the group of associations (abscess-empyema). The epidemiological, clinical, paraclinical, therapeutic and evolutionary data collected on Office 2013 Excel were analyzed. Epidemiological data related to age, sex and gateway, diagnostic elements were clinical (delay between onset of signs and diagnosis, clinical signs) and paraclinical (results of morphological examinations and bacteriology of pus). Therapeutically, this was the antibiotic therapy used and the type of surgical treatment performed. The results were appreciated in terms of lethality and healing. The cured patients were without or with sequelae. The patients cured without sequelae were those who had a normal neurological examination and those with sequelae had a persistence of neurological signs more than three months after treatment.

For this study, we obtained the favourable opinion of the National Ethics Commission.

\section{Results}

\subsection{Epidemiological Data}

Of the 2050 hospitalized patients in 12 years, 41 patients (2\%) were for ICS. Over the same period, 3.4 patients were hospitalized per year. These 41 patients were 
divided into 24 empyems, 8 abscesses and 9 abces-empyeme associations.

The average age was 20.2 years in our entire study. In empyema he was 20.7 years old; 25.6 years for abscesses and 14.1 years for Associations.

Male dominance is noted in all groups. The sex ratio is 3.1 for all of these ICS, 3 for empyema (Figure 1), 2 for abscess and 3.5 for Associations (Figure 2).

Scalp and facial infections (malignant facial staphylococcal disease, palpebral infections, scalp suppuration) were associated with ICS in 12 cases $(29.2 \%)$ with a significant percentage in group empyema of $40 \%$. The ORL origin was found in 17 cases (41.4\%) with sinusitis which represent $29.2 \%$ of cases and otitis, 12.2 cases. Traumatic causes were noted in only 2 cases (4.9\%) for all ICS. Unidentified or cryptogenic sources account for 10 cases $(24.4 \%)$ for the entire study.

These patients remained hospitalized for a period ranging from 12 to 26 days with an average of 16.2 days in general. This average was 12.1 days for empyemas, 21 days for abscesses and 16.2 days for associations.

\subsection{Clinical Data}

The delay between onset of symptoms and diagnosis was, on average, 28.3 days.

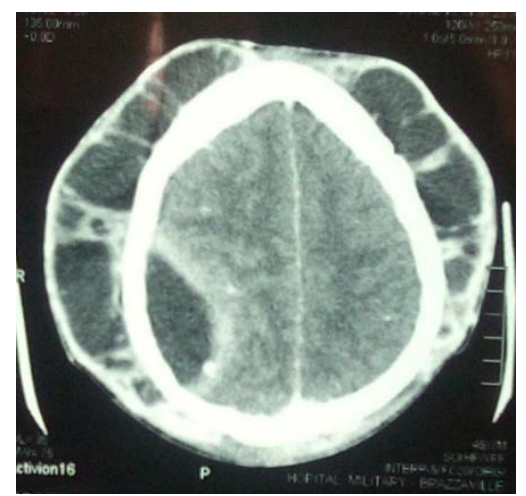

Figure 1. Cranio-encephalic CT scan axial sections after injection of the contrast product showing multiple purulent subcutaneous fronto-biparietal collections and right parietal empyema.

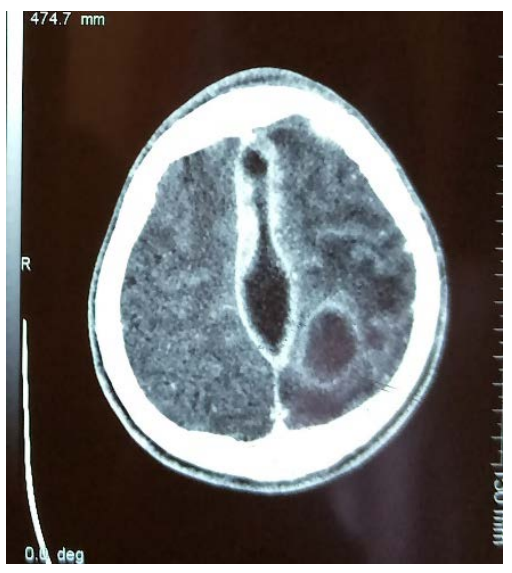

Figure 2. Cranio-encephalic CT scan axial sections after injection of the contrast medium showing a left parietal abscess and interhemispheric empyema association. 
This average delay was 17 days for empyemas; 66.6 days for abscesses and 28.1 days for Associations. This beginning was almost always progressive (97\%).

The clinical signs are grouped in Table 1.

\subsection{Para-Clinical Data}

The morphological assessment was made of CT alone in 37 cases (90\%), MRI alone in 3 cases (7.3\%) and the combination of the two examinations in 2 cases (4.8\%). Three patients had two CTs because of worsening clinical condition.

Lesions were mostly supratentorial. Table 2 gives the different locations. Overall, single lesions accounted for $63.4 \%$ and multiples for $36.6 \%$.

From a biological point of view, HIV serology was performed in 37 patients and 2 positives results (5.2\%). Hyperleukocytosis was noted in $72.7 \%$, sedimentation rate (SR) of red blood cells accelerated in $75 \%$ of cases, and C-reactive protein (CRP) greater than $10 \mathrm{mg} / \mathrm{ml}$ in $76.6 \%$ of cases. Pus analysis was performed in only 34 patients (82.9\%). It had isolated the germs in $29.4 \%$ of cases. $\mathrm{Ta}$ ble 3 gives results of bacteriology test of pus. The infections were mono-microbial.

Table 1. Clinical signs.

\begin{tabular}{cccccccc}
\hline Symptoms & \multicolumn{2}{c}{ Empyema $(\mathrm{n}=24)$} & Abscess $(\mathrm{n}=8)$ & $\begin{array}{c}\text { Association } \\
(\mathrm{n}=9)\end{array}$ & \multicolumn{2}{c}{ Total $(\mathrm{n}=41)$} \\
\hline Headache & 4 & 16.7 & 1 & 1 & 6 & 14.6 \\
Fever & 2 & 8.3 & 1 & 1 & 4 & 9.7 \\
Comitiales crisis & 3 & 12.5 & 1 & 1 & 5 & 12.2 \\
Consciousness disorder & 2 & 8.3 & 1 & 1 & 4 & 9.7 \\
Meningeal syndrom & & & & 1 & 1 & 2.4 \\
Bergman Triad & 13 & 54.2 & 4 & 4 & 21 & 51.2 \\
\hline
\end{tabular}

*The Bergman's triad associates the syndrome of intracranial hypertension, the infectious syndrome and the signs of neurological focus.

Table 2. Lesions location.

\begin{tabular}{cccccc}
\hline Topography & Empyema & Abscess & Association & \multicolumn{2}{c}{ Total } \\
\cline { 5 - 7 } & 24 & 7 & 9 & 40 & 97.5 \\
\hline Supratentorial locations & 14 & 3 & 9 & 26 & 63.4 \\
Isolated locations & 7 & 3 & 6 & 16 & 39 \\
Frontal & 5 & & 1 & 6 & 14.6 \\
Interhemispheric & 2 & & 1 & 3 & 7.3 \\
Parietal & 10 & 4 & 1 & 15 & 36.6 \\
Associated locations & 5 & 1 & 1 & 7 & 17 \\
Fronto-Parietal & 3 & 1 & & 4 & 9.7 \\
Parieto-Temporal & 2 & 1 & & 3 & 7.3 \\
Other & & 1 & & 1 & 2.4 \\
Infratentorial location & & & & & \\
\hline
\end{tabular}


Table 3. Results of bacteriology test of pus.

\begin{tabular}{lcccc}
\hline \multicolumn{1}{c}{ Germs } & Empyema & Abscess & Association & Total \\
\hline Negative test & 7 & 4 & 6 & 24 \\
Positif test & 4 & 1 & 1 & 10 \\
Cocci Gram + & 2 & 2 & 1 & 5 \\
- Streptococcus & 1 & 1 & 1 & 3 \\
-Staphylococcus & & & 1 & 1 \\
Bacilles Gram - & & 1 & & 1 \\
Pseudomonas & & & & \\
\hline
\end{tabular}

\subsection{Therapeutic and Evolutionary Data}

The treatment instituted was exclusively medical for the 8 cases (19.5\%) with lesions smaller than $2 \mathrm{~cm}$. For the 33 cases $(80.5 \%)$ with measurements greater than $2 \mathrm{~cm}$, it was medical-surgical. Tri-antibiotic therapy administered in these patients was often probabilistic because of the low isolation of the germs. The most common associations were those using a 3rd generation Cephalosporin and Imidazole, supplemented with Aminoglycoside in $68.3 \%$ or Fluoroquinolone in $19.5 \%$. Anti-comitial was added to this treatment in $66.6 \%$ overall and corticosteroids in $6 \%$ of the whole abscess and Associations. The surgical management was done within an average of 1.5 days ( 1 and 3 days). It consisted of the evacuation of pus from a trephine hole in all operated patients (84.8\%). Three patients had been re-operated. Treatment of the infection source was performed in 31 patients (75.6\%).

Evolution could only be appreciated in 37 patients (90.2\%), four patients (9.2\%) died. This development was, after three months of medical follow-up, healing without and with the sequelae respectively in $70.7 \%$ and $19.5 \%$.

The evolution following the treatment is recorded in Table 4.

\section{Comments}

ICS are rare but still serious conditions, especially in Africa [3] [4] [5].

Affected subjects generally have an average age of less than 30 years. This age is even lower in the patients of associations group (14.1 years). The male predominance found in our study is noted in many studies [3] [4] [5] [6], except that of Diallo [7] in Mali.

This is often the complications of loco-regional infections that include sinusitis infections are the most common cause with a rate identical to that of scalp and facial infections (29.2\%). These sinusitis are also the first entry into the studies of Broalet [4], Ouiminga [6] and Diallo [7]. Miniar [8] ranks them in first position with meningitis. For Boumediane [9], Sichiziya [10], Idowu [11], Nathoo [12], it is mainly otitis. Traumatic causes were found only in $4.9 \%$ of cases, unlike Sichiziya [10] and Kabré [5] who found them in first position with respectively 
Table 4. Patient's evolution.

\begin{tabular}{lccccc}
\multicolumn{1}{c}{ Evolution } & Empyema & Abscess & Association & \multicolumn{2}{c}{ Total } \\
\hline Healing Without Sequelae & 17 & 5 & 7 & 29 & 70.7 \\
Healing with Sequelae & 4 & 2 & 2 & 8 & 19.5 \\
- Epilepsy & 3 & 1 & 1 & 5 & 12.2 \\
- Motor Deficit & 1 & 1 & 1 & 2 & 4.9 \\
- Behavioral disorder & & 1 & & 1 & 2.4 \\
Deaths & 3 & & & 4 & 9.7 \\
\hline
\end{tabular}

$44 \%$ and $25 \%$ of cases. Metastatic causes were not noted. The share of cryptogenic origins remains important in our study (24.4\%). This is the case of Ouiminga [6] and Kanikomo [13], while Boumediane [9] (14.1\% abscess and 8.7\% for empyema) and Anwary [14] (10.3\%) have lower rate. The symptoms appeared gradually and the time from onset to diagnosis averaged 28.3 days overall. This delay was longer (66.6 days) for abscesses and shorter (17 days) for empyemas and between the two, the association was 28.1 days. In our context, it corresponds to what can be described as a period of "diagnostic wandering". Indeed, patients often come from medical centers or departments where morphological examinations are performed late despite the sometimes evocative clinical pictures. The antibiotic therapy prescribed in these patients is probably at the origin, among other things, of the modification of the various clinical pictures.

These clinical signs were dominated in this study by the Bergman's triad, found in $51.2 \%$ of cases in general. Its percentage in empyema is $54.2 \%$, and half of cases in abscesses and associations. Djientcheu [15] found it in $51.86 \%$ and Broalet at $94 \%$. For the above mentioned cause, this triad is weakly present at admission for other authors [6] [9]. It was followed by fever, and headache with $14.6 \%$, seizures of $12.2 \%$ and fever and consciousness disorder in $9.7 \%$ each.

The place of modern morphological examinations in the diagnosis of ICS is unanimously recognized. CT alone, often gave the diagnosis. Diagnosed doubts had MRI prescribed in 2 patients. These examinations revealed a predominance of empyemas over abscesses and the association of the two lesions. This distribution is found by Broalet [4] but, contrary to that Code [3]. Their location is almost exclusively supratentorial with a predominance of the head office, alone or associated with other regions. This observation is made by almost all authors. However, Anwary [14] finds, in his study, a significant proportion of infratentorial sites equal to those of the intracranial parietal regions.

While HIV-acquired immunodeficiency has allowed outbreaks of some ICS such as cerebral toxoplasmosis, it has not been observed in ICS with banal germs. HIV serology was positive in only $5.2 \%$ of cases and Broalet [4] in 12 patients found no positive serology. The leukocytosis, the acceleration of the sedimentation rate and the increase in C-reactive protein reported by some authors [6] [10], and found during our study (almost 3 times out of 4), constitute for us, 
elements of biological monitoring of ICS. Pus analysis was only performed in 34 patients. It had isolated the germs in $29.4 \%$ of cases. These were mono-microbial infections and the isolated organisms were Gram-positive Cocci in 8 cases and Gram-negative Bacilli in 2 cases. Streptococcus isolated in 5 cases was the most found germ, followed by Staphylococcus (3 cases). The anaerobic germs had not been isolated. The low rate of positivity of bacteriological examinations and the prevalence of Gram positive Cocci were noted by Ba [3] and Ouiminga [6] in Senegal, as well as Miniar [8] in Tunisia. The antibiotherapy of the period of "diagnostic wandering", poor conditioning of pus may explain this low positivity of the examinations and the absence of anaerobic germs, which we and other authors [8] [13] have noted. These anaerobic germs are predominant in the bacteriological study of Merad [16] in Algeria.

The use of new medical imaging techniques, new antibiotic molecules, new surgical techniques has significantly reduced the mortality of these diseases since the 1970s [1] [12]. However, its usual probabilistic orientation, supported in particular by the low contribution of bacteriological examinations, is one of the weaknesses of this care in our countries. The duration of this antibiotic therapy varies and depends on the country. The use of modern techniques in bacteriology will allow orientation towards targeted antibiotic therapy. While waiting for all these advances, the third-generation cephalosporin combination, aminoglycoside and metronidazole was the most used in our series as well as in other authors [6] [9] [17]. Anti-epilepsies and anti-edematous drugs were quite often associated with antibiotics. Halmani [18] attributes to them an improvement in vital and functional prognosis. The surgical treatment used a simple technique for the evacuation of pus. This is the trepano-puncture used by many authors [3] [19]. The bony opening has been widened in the empyema, to facilitate that of the dura mater. The operative revisions used the same operative technique. The excision of the hull has not been practiced in our series. Boumediane [9] and Hassani [20] justify it in recurrences and cases of intra-cavitary foreign body, which we did not have. The stereotactic puncture that Hassani [20] reported in $34.15 \%$ and by Chaoui quoted by Hassani in $59.1 \%$, was not practical because it was not available. The treatment of the infection origin is imperative to avoid recurrences [1]. Preventing these infections seems to us to be the best option. Indeed, the action on the sources of these infections, largely represented by ORL infections, will reduce these ICS. Despite our medical practice in the area of certain diseases such as malaria, we must know how to evoke these ICS in some patients as noted Kabré [5]. Early management of these conditions will limit the treatment to the medical component essentially.

Under this treatment, healing without sequelae was noted in $70.7 \%$. Those with sequelae accounted for $19.5 \%$ of epilepsy (12.2\%) who was predominating. The mortality was $9.5 \%$. This evolution of our patients and, reported by most authors, confirms the benefit brought by the triple contribution of novelties in medical imaging techniques, antibiotic molecules and surgical techniques. 


\section{Study Strengths and Limitations}

The study identified the problems related to the management of intra cranial suppuration in Brazzaville. These difficulties are useful bases to initiate the change of this support.

The limit of the study was especially its retrospective character.

\section{Conclusion}

CIS is still a health problem in Africa because of its worrying lethality. Complication of loco-regional and remote infections, adequate treatment of these sources can significantly reduce their morbidity and mortality.

\section{Author's Contributions}

L Boukassa designed and wrote the manuscript, OB Ngackosso and SB Kinata Bambino collected the data, HE Ekouele Mbaki dealt with statistical aspects.

\section{Acknowledgements}

Thanks to Mr Tresor Macillat for her contribution to this article.

\section{Conflicts of Interest}

The authors declare no conflicts of interest regarding the publication of this paper.

\section{References}

[1] Leys, D. (2001) Abcès cérébraux et empyèmes intracrâniens. Encycl Méd Chir, Neurologie. 17-485-A-10, 7 p.

[2] Laurichesse, J.-J., Souissi, J. and Leport, C. (2009) Abcès du cerveau. EMC. (Elsevier Masson SAS, Paris) Traité de Médecine Akos. 4-0975. https://doi.org/10.1016/S1634-6939(09)45383-3

[3] Ba, M.C., Kachungunu, C.M., Mudekereza, P.S., Ly Ba, A., Thiam, A.B., Beketi, A., et al. (2014) Les suppurations collectées intracrâniennes à Dakar: A Propos De 125 Cas. Journal de Neurochirurgie, 19, 17-25.

[4] Broalet, E., N'dri Oka, D., Eholie, S.P., Guillao-Lasme, E.B., Varlet, G. and Ba Zeze, V. (2002) Abces et empyemes intracraniens chez l'enfant observes à Abidjan (Côte d'Ivoire). African Journal of Neurological Sciences, 21, 38-41. https://doi.org/10.4314/ajns.v21i1.7517

[5] Kabré, A., Zabsonré, S., Diallo, O. and Cissé, R. (2014) Prise en charge médico-chirurgicale des abcès du cerveau à l'ère du scanner en Afrique sub-saharienne: À propos de 112 cas. Neurochirurgie, 60, 249-253. https://doi.org/10.1016/j.neuchi.2014.06.011

[6] Ouiminga, H.A.K., Thiam, A.B., Ndoye, N., et al. (2014) Les empyèmes intracrâniens: Aspects épidémiologiques, cliniques, paracliniques et thérapeutiques. Étude rétrospective de 100 observations. Neurochirurgie, 60, 299-303. https://doi.org/10.1016/j.neuchi.2014.06.015

[7] Diallo, M., Traore, Y., Faye, M., Coulibaly, A., Kanikomo, D. and Diallo, O. (2017) Les empyèmes intracrâniens: Aspects diagnostiques et thérapeutiques dans le ser- 
vice de neurochirurgie du chu Gabriel Toure à propos d'une série de 32 cas. Rev. Cames Sante, 5, 64-69.

[8] Miniar, T., Amel, B.A., Khalil, S., Ben Helal, B.H.K., Gueddiche, G.M.N., Tilouche, T.S., et al. (2018) Pyogenic Brain Abscess in Children: A Tunisian Multi-Center Experience. African Health Sciences, 18, 560-568. https://doi.org/10.4314/ahs.v18i3.13

[9] Boumediane, E.M. (2016) La prise en charge des suppurations Intracrâniennes "A propos de 170 cas" au service de Neurochirurgie CHU Mohamed VI Marrakech. Thèse Méd Marrakech. No. 10.

[10] Sichizya, K., Fieggen, G., Taylor, A. and Peter, J. (2005) Brain Abscesses-the Groote Schuur Experience, 1993-2003. South African Journal of Surgery, 43, 79-82.

[11] Idowu, O.E. and Majekodunmi, A.A. (2016) Relationship between Demography, Etiology, Level of Consciousness, and Outcome of Surgical Intracranial Suppurations of Bacterial Origin in a Tropical Tertiary Center. Asian Journal of Neurosurgery, 11, 41-45. https://doi.org/10.4103/1793-5482.165798

[12] Nathoo, N., Naadvis, S.S., Van Dellen, J.R. and Gows, E. (1999) Intracranial Subdural Empyemas in the Era of Computed Tomography: A Review of 699 Cases. Neurosurgery, 44, 529-535. https://doi.org/10.1097/00006123-199903000-00055

[13] Kanikomo, D., Diallo, O., Sogoba, Y., Maiga, Y., Diop, A.A., Traore, H., et al. (2013) Aspects cliniques et thérapeutiques des abcès cérébraux: 17 cas colligés au CHU Gabriel Toure à Bamako. Mali Medical, 28, 15-18.

[14] Anwary, M.A. (2015) Intracranial Suppuration: Review of an 8-Year Experience at Umtata General Hospital and Nelson Mandela Academic Hospital, Eastern Cape, South Africa. South African Medical Journal, 105, 584-588. https://doi.org/10.7196/SAMJnew.7882

[15] Djientcheu, V.P., Mouafo, T.F., Esiene, A., Kamga, Y.N., Nguefack, S., Bello, F., et al. (2013) Intracranial Suppurations in the African Child: A Severe But Preventable Complication. Child's Nervous System, 29, 119-123. https://doi.org/10.1007/s00381-012-1930-6

[16] Merad, A.S. (1999) Etude bactériologique des suppurations intracrâniennes dans la région d'Alger entre 1987 et 1996. Archives de PInstitut Pasteur d'Algérie, 63, 89-109.

[17] Thobejane, E.K. (2012) The Outcome of Intracranial Subdural Empyema at Steve Biko Academic Hospital: Retrospective Study. Master of Medicine in Neurosurgery Faculty of Health Sciences, University of Pretoria, Hatfield.

[18] Hilmani, S. (2008) Les empyèmes intracrâniens. Thèse Med Casablanca No. 222.

[19] Loembe, P.M., Okome-Kouakou, M. and Alliez, B. (1997) Les suppurations collectées intracrâniennes en milieu africain. Medecine Tropicale, 5, 186-194.

[20] Hassani, F.D., El Fatemi, N., Moufid, F., Oudrhiri, M.Y., Gana, R., El Maaqili, R., et al. (2014) Abcès encéphaliques: Prise en charge, à propos d'une série de 82 cas. The Pan African Medical Journal, 18, 110. https://doi.org/10.11604/pamj.2014.18.110.2247 